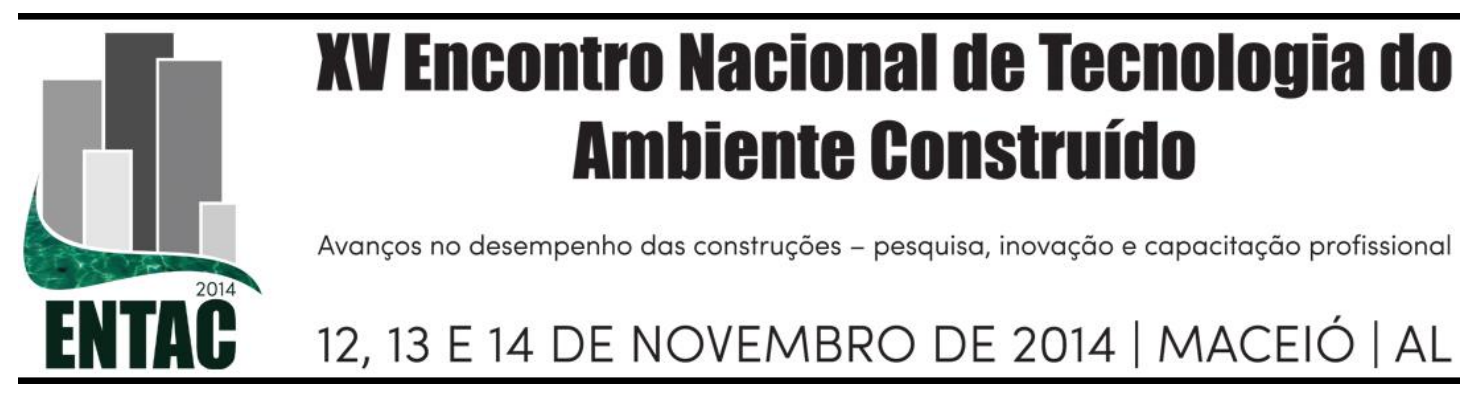

\title{
RESÍDUOS DE GESSO NA CONSTRUÇÃO CIVIL - REUTILIZAÇÃO E/OU RECICLAGEM NO RN
}

\author{
PEREIRA, Milena (1); FERREIRA, João (2); OLIVEIRA, Michelli (3)
}

(1) UNIFACEX, (84) 9617-9595, e-mail: milena katharina @ hotmail.com, (2) UNIFACEX, e-mail: joao.leiteandrade@ hotmail.com, (3) UNIFACEX, e-mail: michelliso@gmail.com.

\begin{abstract}
RESUMO
A utilização do gesso na construção civil apresenta-se cada vez mais difundida devido a aspectos como baixo custo de produção e fino acabamento. Consequentemente problemas foram gerados com relação ao seu descarte, tanto ambientais quanto econômicos. A busca por uma logística reversa na reutilização do gesso levou a um projeto de pesquisa de caráter exploratório-descritivo, com o objetivo de investigar e avaliar a real destinação dos resíduos de gesso nas empresas do Rio Grande do Norte, assim como seu conhecimento e comportamento a respeito da temática, e, por conseguinte, verificar como pode e deve ser feito o efetivo reaproveitamento e reciclagem do material. Com base nisso, a metodologia utilizada fez uso da técnica de pesquisa bibliográfica a fim de entender e dominar as características físico-químicas do gesso, seu custo de processamento e de transporte, o preço da matéria prima natural, a gestão dos seus resíduos, dentre outras informações acerca dos projetos que vêm sendo desenvolvidos na área, por meio de levantamento de dados. De forma complementar, o uso da pesquisa de campo possibilitou a realização de visitas in loco, para realização de uma pesquisa quantiqualitativa. Diante disso, um questionário serviu de pré-teste e foi aplicado às empresas associadas ao SINDUSCON/RN, com intuito de analisar o seu grau de conhecimento, destinação, gerenciamento e reutilização do gesso. Os resultados alcançados apontam para uma nova fase da pesquisa, onde foi construído um instrumento de coleta de dados específico, de acordo com a realidade apresentada, a fim de se obter uma visão mais clara dos reais procedimentos adotados nas empresas para destinação do gesso. O questionário, fruto desta análise foi aplicado em 23 empresas, as quais apresentaram as primeiras evidências quanto ao comportamento de destinação do gesso.
\end{abstract}

Palavras-chave: Construção civil, Reutilização, Gesso.

\begin{abstract}
The use of plaster in construction presents increasingly diffused due to aspects such as low production and fine workmanship. Consequently problems were generated with respect to its both environmental and economic disposal. The search for a reverse logistics reuse of plaster led to research project descriptive exploratory study aiming to investigate and evaluate the actual allocation of plaster waste companies in Rio Grande do Norte, as well as their knowledge and behavior of the theme, check how can and should be made effective reuse and material recycling. Based on this, the methodology made use of the technique of literature in order to understand and master the physicochemical characteristics of the gypsum cost of processing and transport, the price of natural raw materials, the management of their waste, among other information about the projects being developed in the area through survey data. So we tried to make visits in loco, Quantiqualitative for performing a search. Therefore, a questionnaire served as the pretest and the companies associated to SINDUSCON / RN was applied, in order to analyze the degree of knowledge, disposition, management and reuse of plaster. The results obtained indicate a new phase of the research, which was built an instrument to collect specific data, according to the reality presented in order to obtain a clearer image of the actual procedures used by companies to dispose of plaster. The questionnaire, the result of this analysis was applied to 23 companies, which were the first evidence regarding the behavior of dispose of plaster.
\end{abstract}




\section{INTRODUÇÃ̃O}

A presente pesquisa tem o objetivo de investigar e avaliar a real destinação dos resíduos de gesso nas empresas do Rio Grande do Norte, assim como seu conhecimento e comportamento a respeito da temática, e, ainda, propor um melhor reaproveitamento e reciclagem do material.

A metodologia de caráter exploratório-descritivo abrangeu uma pesquisa bibliográfica, a fim de entender e dominar as características físico-químicas do gesso, seu custo de processamento e de transporte, o preço da matéria prima natural, a gestão dos seus resíduos, dentre outras informações acerca dos projetos que vêm sendo desenvolvidos na área, por meio de levantamento de dados, além de uma pesquisa de campo quanto a seus procedimentos,onde foram também realizadas visitas in loco e a aplicação de um questionário nas empresas associadas ao SINDUSCON/RN.

Pôde-se verificar que entre os diferentes segmentos da cadeia produtiva da construção civil, o segmento gesseiro apresenta um grande potencial de contribuição para a sustentabilidade da indústria da construção, devido ao baixo consumo energético do processo de produção e da viabilidade de reciclagem dos resíduos gerados ao longo de sua cadeia produtiva (JOHN, ANGULO, CINCOTTO,2002).

A experiência internacional mostra que a reciclagem do resíduo de gesso é viável, sendo adotada nos EUA e Europa, especificamente, no setor de beneficiamento de chapas acartonadas (PINHEIRO,2011).

O interessante é que desde 2001 a reciclagem desse resíduo teve início na Europa, enquanto que no Brasil no mesmo período foi classificado pelo Conselho Nacional de Meio Ambiente (CONAMA), 307/02 como classe "C", ou seja, resíduos para os quais não foram desenvolvidas tecnologias ou aplicações economicamente viáveis para reciclagem ou recuperação. Só passou por uma reclassificação em 2011 sendo considerada classe "B", reciclável para outras destinações. Isso ocorreu em função de pesquisas recentes que mostraram que o gesso pode ser reciclado diversas vezes e reinserido em sua própria cadeia produtiva ou mesmo em outros tipos de uso e também em função do interesse dos fabricantes.

Devido a isso, é necessário que a indústria da construção civil adote os sistemas de logística reversa, que têm por objetivo desenvolver cadeias reversas para o reaproveitamento dos produtos e resíduos originados nos processos produtivos e estabelecer nos agentes que nela atuam o censo de responsabilidade por todo o ciclo de vida do produto (QUERINO, 2013).

É importante saber que as características físico-químicas do resíduo exigem cuidados especiais na sua disposição final, devido ao seu potencial tóxico, à liberação de gases inflamáveis, ao risco de contaminação do solo e do lençol freático, bem como em razão das restrições aos percentuais de uso em agregados reciclados oriundos dos resíduos da construção civil (JOHN, ANGULO, CINCOTTO, 2002). Entretanto, a reversibilidade de suas reações de transformação possibilita, por meio de um processo simples de reciclagem, a inserção do resíduo nos diferentes setores da sua cadeia produtiva.

\section{REVISÃO BIBLIOGRÁFICA}

A gipsita também conhecida como "gipso" se configura um mineral abundante na natureza, cuja fórmula estequiométrica é CaSO4.2H2O.Pode-se dizer então que sua constituição química é basicamente: 32,5\% de $\mathrm{CaO} 3 ; 46,5 \%$ de SO3 e 20,9\% de $\mathrm{H} 2 \mathrm{O}$. 
Por ser um mineral pouco resistente, sob a ação do calor, em torno de $160^{\circ} \mathrm{C}$, sofre desidratação parcial o que provoca a obtenção do material denominado gesso ( $\mathrm{CaSO} 4.1 / 2 \mathrm{H} 2 \mathrm{O})$.

Sabe-se que a gipsita é facilmente encontrada em bacias sedimentares, o Brasil, por possuir cerca de $60 \%$ do seu território recoberto por essa formação, possui vários depósitos de gipsita, sendo os principais: Bacia Amazônica (Amazonas e Pará), Bacia do Meio Norte ou Bacia do Parnaíba (Maranhão e Tocantins), Bacia Potiguar (Rio Grande do Norte), Bacia Sedimentar do Araripe (Piauí, Ceará e Pernambuco) e Bacia do Recôncavo (Bahia) (LYRA SOBRINHO et al. 2011).

Em 2010, segundo o Departamento Nacional de Produção Mineral (DNPM), foram produzidas no Brasil cerca de 2750 mil toneladas de gipsita, enquanto foram consumidas 2820 mil toneladas desse mineral. O estado de Pernambuco, principal produtor do Brasil, foi responsável por $91,5 \%$ da produção nacional, tendo como destaque o chamado "polo gesseiro do Araripe", situado no extremo oeste pernambucano e formado pelos municípios de Araripina, Trindade, Ipubi, Bodocó e Ouricuri. Os demais estados produtores de gipsita são: Maranhão (4,9\%), Ceará $(2,4 \%)$, Amazonas $(1,1 \%)$ e Tocantins $(0,1 \%)$ (LYRA SOBRINHO et al. 2011). Segundo o próprio DNPM, a produção de gipsita no Brasil aumentou para 3223 mil toneladas em 2011 e para 3750 mil toneladas (dado preliminar) em 2012 (AMORIM NETO, DANTAS, 2013).

No que se refere às empresas produtoras, as de maior destaque são: Votorantim Cimentos N/NE, Mineradora São Jorge S/A, CBE - Companhia Brasileira de Equipamento (Grupo João Santos), Mineradora Campevi Ltda e Holcim S/A, juntas elas produzem mais de $60 \%$ de toda a produção nacional.

O gesso utilizado na construção civil é denominado gesso "beta", que por possuir um custo de processamento menor, tem características como resistência mecânica, consistência e tempo de pega inferior ao ideal, tudo isso devido ao formato irregular dos cristais obtidos.

Como o gesso é um dos materiais mais usados na construção civil, devido a sua ampla variabilidade de uso (fabricação de blocos e placas, revestimentos, moldes cerâmicos, forros, acabamentos) com o passar dos anos sua utilização tornou-se cada vez mais acelerada, seu desenvolvimento e técnicas de aplicação foram se aperfeiçoando, concomitantemente o seu descarte nos aterros de construção civil também, uma vez que o quantitativo de resíduos provenientes do gesso equivale a $4 \%$ de todo resíduo gerado nos canteiros de obra.

No entanto, aliado a isso começa a surgir à cultura do "reduzir-reusar-reciclar", influenciada sem dúvidas pela alteração do Conselho Nacional de Meio Ambiente (CONAMA). Na resolução 307/02 o gesso era classificado como "classe C" (resíduos para os quais não foram desenvolvidas tecnologias ou aplicações economicamente viáveis para reciclagem ou recuperação), ou seja, era considerado como lixo. Hoje a nova resolução do CONAMA 431/11 permite que o gesso passe a ocupar a "classe B", e consequentemente, possua tecnologia viável para sua reciclagem.

Segundo as informações da SINDUSGESSO e ABRAGESSO as principais fontes de resíduos de gesso na construção civil são as atividades de revestimento (88\%), chapas de gesso acartonado (8\%) e os componentes pré-moldados $(4 \%)$ que são responsáveis pelo consumo direto de 1.090 .000 toneladas do minério por ano e produzem uma massa aproximada de 120 mil toneladas de resíduos somente na grande São Paulo. Esses resíduos, se devidamente gerenciados, poderiam minimizar o consumo de gipsita em 32.700 toneladas por ano (AGOPYAN, A. K. et al. 2005). 


\section{METODOLOGIA}

Foi realizado um estudo bibliográfico qualiquantitativo abrangendo as principais informações sobre a aplicabilidade do gesso na construção civil, o preço da matériaprima natural e do transporte, seu custo de processamento, quantidade de resíduos de gesso nas indústrias e a gestão desses resíduos.

Além disso, foi realizado um levantamento do número de construtoras norte-riograndenses através do Sindicato da Indústria da Construção Civil (SINDUSCON), a fim de coletar dados necessários para o desenvolvimento da pesquisa. O questionário abordava os mais variados temas interligados à sustentabilidade empregada na construção civil, dentre eles: gerenciamento do resíduo, práticas sustentáveis e sua destinação.

Logo após, foi aplicado um questionário do tipo fechado a fim de obter a quantidade de empresas que desenvolvem métodos e técnicas para minimizar os problemas causados por suas obras, bem como o gerenciamento de resíduos, particularmente o caso do gesso, e a economia gerada naquelas que possuíam programas sustentáveis.

\section{RESULTADOS E DISCUSSÕES}

A aplicação dos questionários sobre a utilização do gesso nas empresas do Rio Grande do Norte permitiu investigar as práticas relacionadas ao consumo de gesso adotadas por 23 construtoras. Inicialmente, dentre as empresas pesquisadas, 59\% alegam executar atividades voltadas para a aplicação de forros, com e sem cortineiros, em áreas de $100 \mathrm{~m}^{2}$ a $1000 \mathrm{~m}^{2}$ diariamente, com uma redução de custo de $10 \%$ para até $57 \%$ das empresas entrevistadas, em razão da utilização do gesso.

Para $91 \%$ das empresas participantes da pesquisa o desenvolvimento de uma obra visando sua sustentabilidade é fator de diferencial competitivo. No entanto, o que se observa é que, apesar das empresas defenderem este posicionamento, pouco se tem feito para alcançar tal diferencial de forma prática.

\section{Gráfico 1 - Empresas que empregam projetos de sustentabilidade}

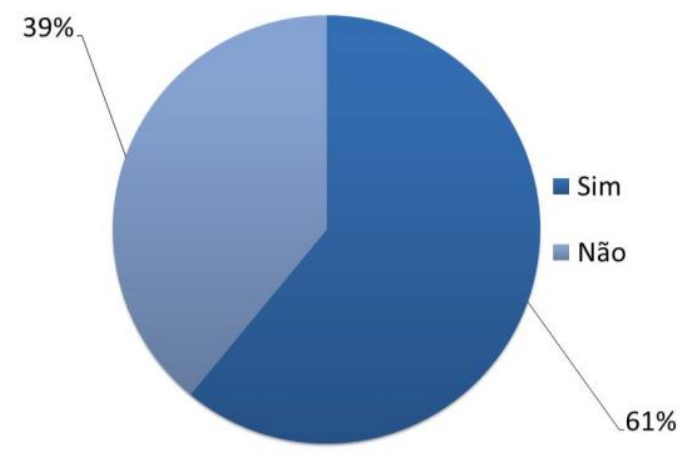

Fonte: Dados da pesquisa (Março, 2014).

A pesquisa também demonstrou que $61 \%$ das empresas desenvolvem algum projeto de sustentabilidade, conforme Gráfico1. Considera-se por projeto com desenvolvimento sustentável apresentar ações que busquem minimizar os impactos causados pela obra, tais como: fiscalização dos canteiros, destinação correta dos resíduos, palestras com seus funcionários, segregação de resíduos, dentre outros. 
Ao identificarmos as ações de sustentabilidade que busquem minimizar os impactos ambientais implementadas nas obras, foi observado que $60 \%$ das empresas adotam práticas relacionadas com o cumprimento da Resolução 306 do CONAMA, como mostra o Gráfico 2 abaixo.

\section{Gráfico 2 - Projetos empregados na obra}

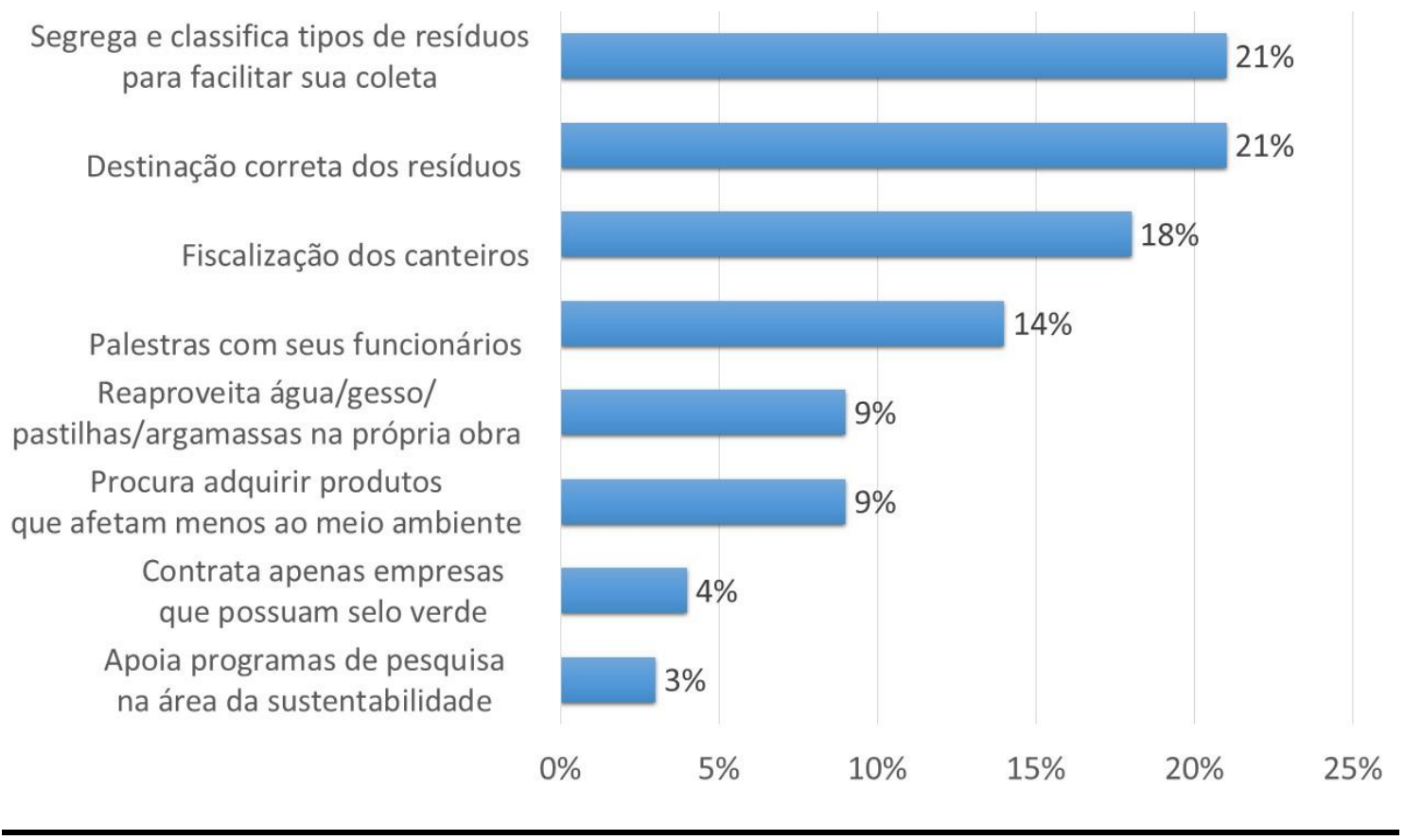

Fonte: Dados da pesquisa (Março, 2014).

Ao tratar do emprego de técnicas de reciclagem do gesso, $96 \%$ das empresas afirmam que não empregam técnicas ou tecnologias de reciclagem e reutilização em nenhuma atividade (Gráfico 3). O mais preocupante, em outra análise deste gráfico, é que $78 \%$ do total destas empresas, desconhecem o que pode ser feito para um melhor reaproveitamento do insumo, ficando somente na tentativa de aproveitar ao máximo o gesso durante a execução das obras.

\section{Gráfico 3 - Emprego de técnicas de reciclagem}

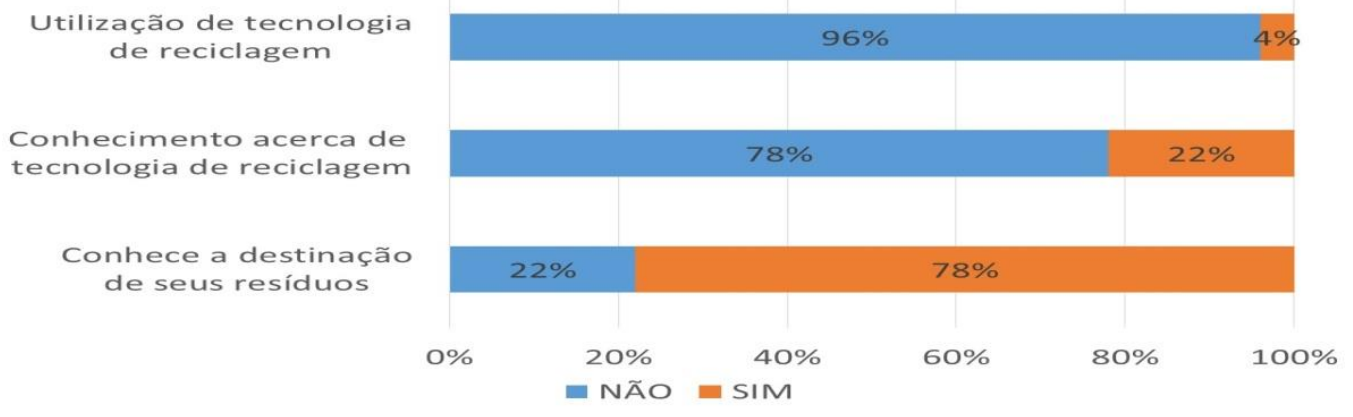

Fonte: Dados da pesquisa (Março, 2014). 
Essa vertente permite visualizar a falta de consciência da importância aliada à ausência de informações, pois apesar de existirem tecnologias, mesmo que poucas, para a reutilização do gesso, o que foi apresentado pelas empresas, é que as mesmas desconhecem os possíveis impactos causados pelos resíduos do gesso. Em uma escala de 1 a 5 foi perguntado sobre o nível de impacto que julgavam ocasionar em suas obras, e $57 \%$ responderam três, ou seja, um valor mediano, apesar da realidade ser bastante diferente.

Já com relação à destinação dos resíduos do gesso, 78\% das empresas afirmaram conhecer seu encaminhamento final, além disso, informaram que esse processo é realizado por mão de obra especializada, a qual se responsabiliza de depositá-los em locais como: usinas (40\%), aterros da construção civil (40\%), dentre outros. Entretanto, quando perguntados utilizando uma escala de 1 a 10 quanto do total aplicado de gesso é depositado em locais adequados para resíduos da construção civil 48\% apontam nível 2, ou seja, depositam em locais inapropriados (Gráfico 4). Consequentemente, o que se pode dizer é que a maioria das empresas ainda não possuem informações consistentes relacionadas à destinação final dos rejeitos.

\section{Gráfico 4 - Metodologia de descarte adequado}

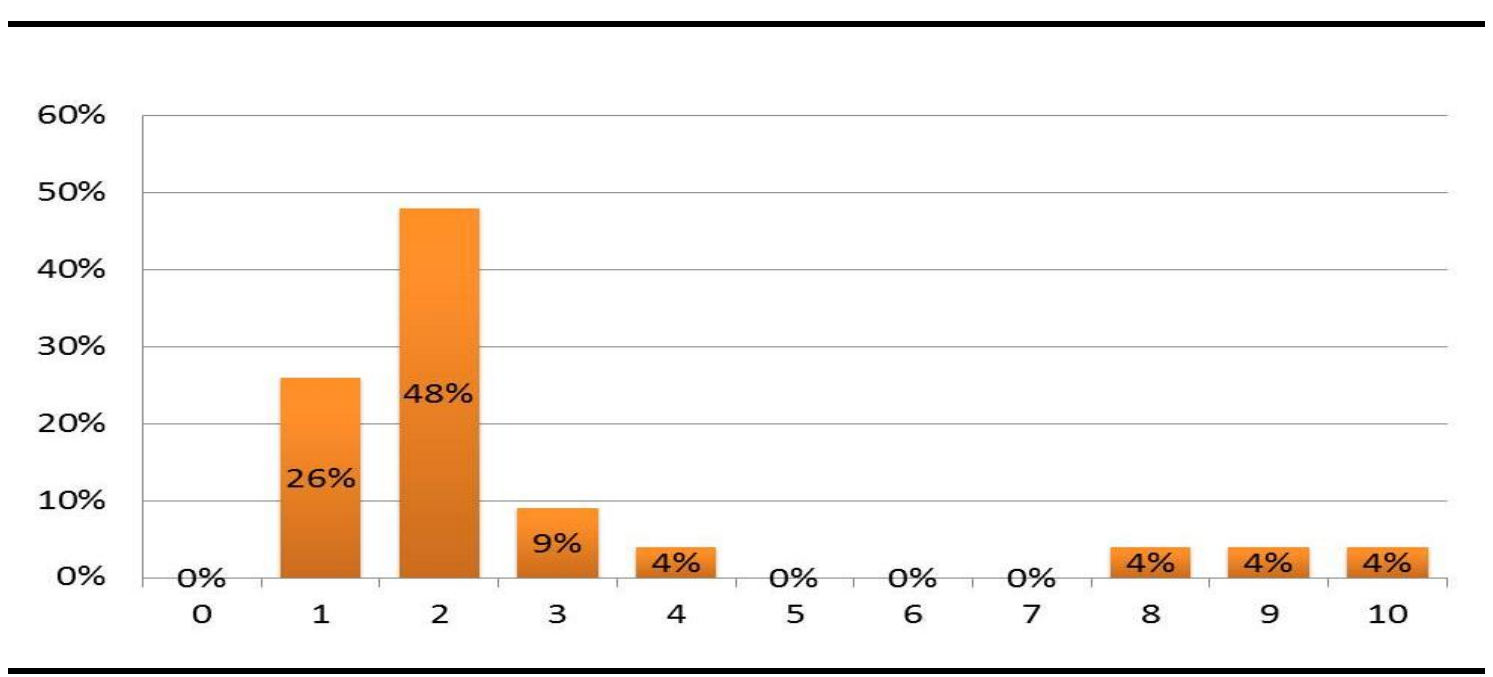

Fonte: Dados da Pesquisa (Março, 2014).

Com base no Gráfico 5, foi observado que $80 \%$ do material desperdiçado durante a realização de uma obra, possui dois destinos, aterros de construção civil e usinas, o restante é distribuído para lixões (8\%) ou fica retido na obra (12\%), ocupando um espaço que poderia ser destinado a finalidade. Com isso, observa-se que boa parte das obras possui um gerenciamento efetivo de seus resíduos, e com a orientação que as empresas alegam dar aos seus instaladores na hora de segregar um material corretamente, a chance desse resíduo vir a ser reaproveitado posteriormente aumenta. 


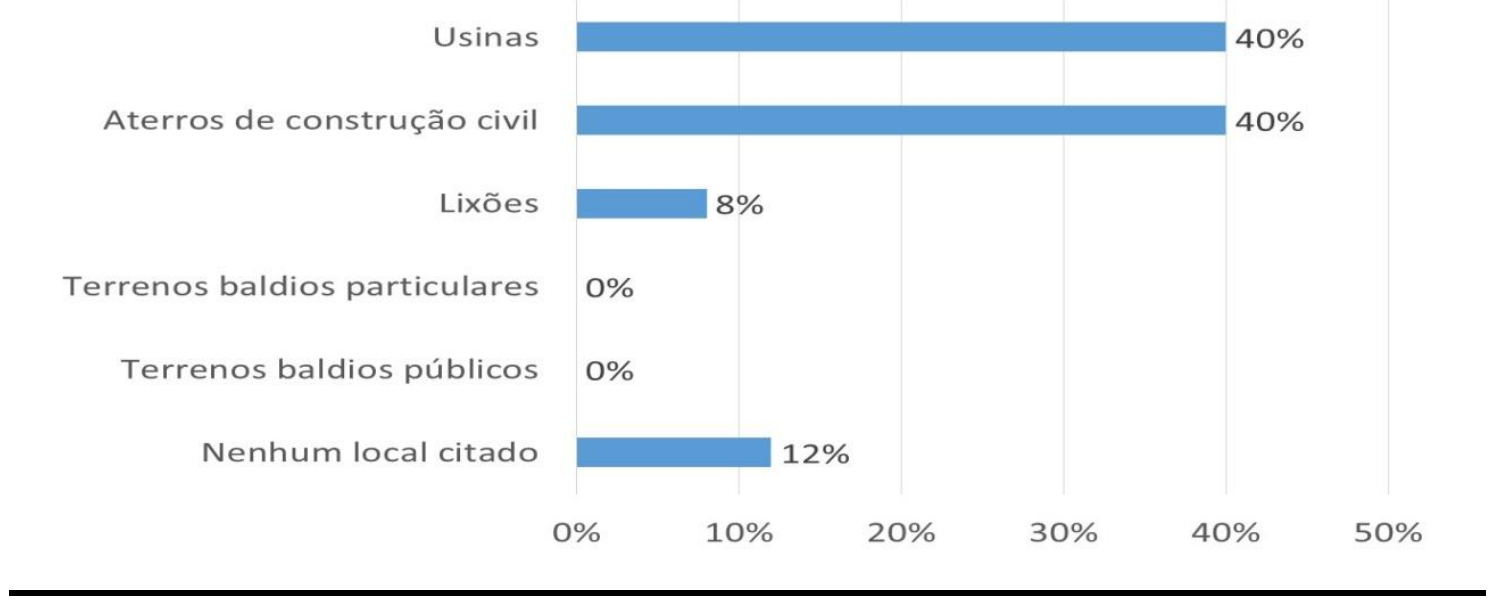

Fonte: Dados da Pesquisa (Março, 2014).

Para atender a demanda quanto à destinação e obtenção da reciclagem de resíduos, oriundos da construção civil foi aberta a ECOBRIT, usina de reciclagem situada no município de São Gonçalo do Amarante/RN, com capacidade de reciclar de 80 a 120 toneladas por dia de rejeitos. Conforme Figura 1, o gesso está estocado esperando seu processamento. O processo de reciclagem se dá através de uma limpeza manual, quebra do material em pequenos pedaços, para então ser triturado por uma enchedeira capaz de deixá-lo na forma de pequenos pedriscos. Esse gesso é destinado às cimenteiras que, após moagem, reutilizam o gesso em seu processo produtivo. Este cimento produzido é vendido na maioria das vezes para as mesmas construtoras, que o encaminharam à ECOBRIT, formando um ciclo de logística reversa.

\section{Figura 1 - Metodologia de descarte adequada}

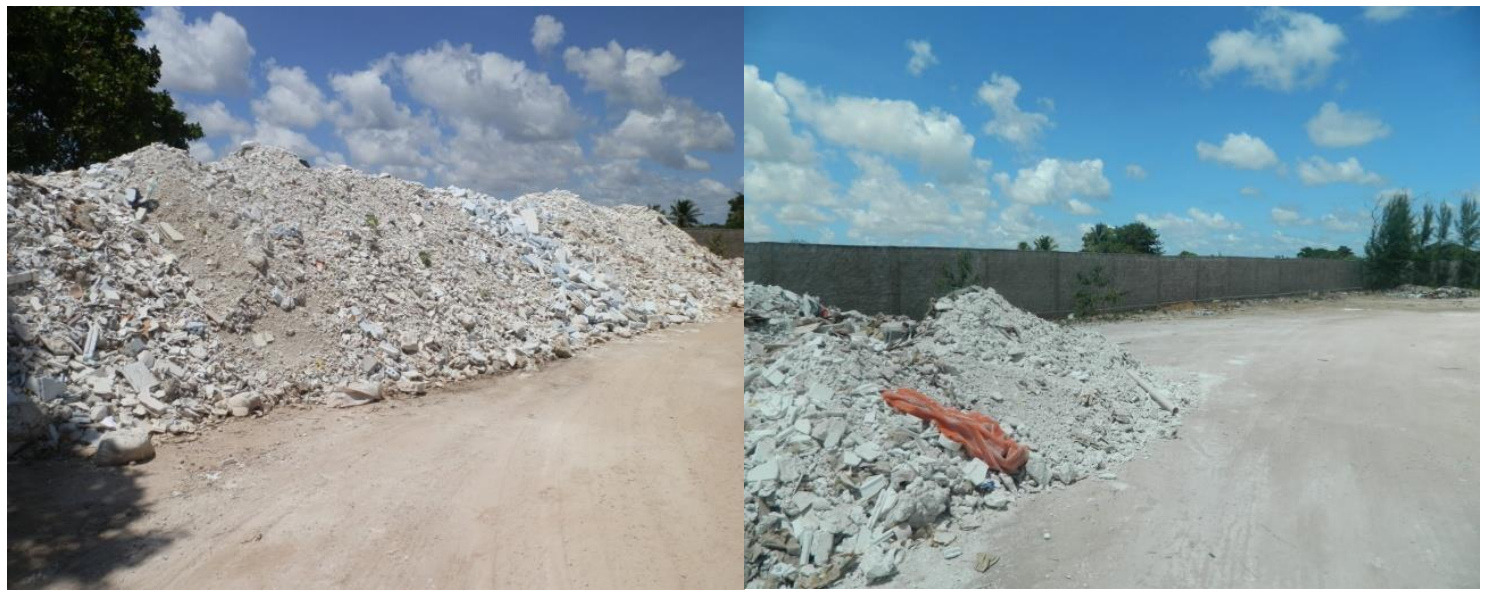

Figura 1 - Gesso aguardando processamento para ser encaminhado às empresas. 
Tabela 1 - Relação de entrada e saída gesso

\begin{tabular}{c|c|c}
\hline Meses de recebimento & Quantidade recebida $\left(\mathrm{m}^{3}\right)$ & Quantidade destinada $\left(\mathrm{m}^{3}\right)$ \\
\hline Janeiro & 120 & 100 \\
\hline Fevereiro & 80 & 70 \\
\hline Março & 110 & 110 \\
\hline Abril & 160 & 40 \\
\hline Total & 470 & 320 \\
\hline \multicolumn{2}{c}{ Custo de frete por tonelada } & $\mathrm{R} \$ 45,00$ \\
\hline
\end{tabular}

Fonte: Dados fornecidos pela ECOBRIT (Março, 2014).

A Tabela 1 apresenta o beneficiamento do resíduo de gesso recebido pela ECOBRIT nos primeiros quatro meses de 2014. Pode-se observar que apesar da reciclagem do material garantir a sua utilização para diversas aplicabilidades, essa prática ainda não é comumente utilizada no Rio Grande do Norte, visto que menos da metade dos resíduos de gesso da construção civil (cerca de 40\%, segundo Gráfico 5) são destinados à reciclagem. Falta de informações, aliado a falta de divulgação e estudos acerca do assunto favorecem essa realidade.

A reciclagem do gesso é, como exposto acima, fácil e relativamente barata, já que o principal custo refere-se ao transporte, e também é extremamente benéfica para o meio ambiente. Por isso, faz-se necessário uma maior inserção da política do reduzirreutilizar-reciclar no Estado, tanto através de maior enfoque no que as empresas estão desenvolvendo, quanto no desenvolvimento de pesquisas, a fim de sempre mostrar que construção civil e sustentabilidade, podem sim permanecer juntas.

\section{CONSIDERAÇÕES FINAIS}

A existência e consequente cobrança de uma legislação específica orientando a correta destinação dos resíduos da construção civil, tem contribuído para um maior cuidado das empresas construtoras do estado do Rio Grande do Norte, quando tratam esta situação.

Entretanto, segundo dados da pesquisa, ainda se verifica um estágio muito inicial de consciência das empresas quanto à importância e benefícios de um gerenciamento adequado desses resíduos, inclusive os do gesso, o que se configura em algumas respostas contraditórias e na falta de dados consistentes sobre a geração e destinação de tais resíduos. Outro fator a considerar é a falta de conhecimento quanto às possibilidades e tecnologias de reciclagem disponíveis.

Quando se tem o resíduo de gesso, a conclusão que se pode ter é que, por ser muito barata sua exploração e produção, o material também é muito barato e, consequentemente, muito utilizado em obra. Isto tem gerado uma grande quantidade de resíduo na região, mas o interesse na reciclagem e reutilização é quase nenhum. No entanto, os maiores cuidados com a destinação têm gerado um resíduo mais limpo e adequado à sua reciclagem e reutilização. Um quadro que é similar ao de muitos outros estados do país e que precisa ser mudado. 


\section{AGRADECIMENTOS}

Ao UNIFACEX, pelo apoio financeiro, ao SINDUSCON/RN e suas empresas associadas, que demonstraram interesse em participar deste trabalho e à ECOBRIT pela disponibilização dos dados para a pesquisa e seus colaboradores que dedicaram tempo para contribuir com a pesquisa de campo.

\section{REFERENCIAS}

AGOPYAN, A. K. et al. Resíduos de gesso: desafios e oportunidades. In: SEMINÁRIO GESTÃO E RECICLAGEM DE RESÍDUOS DE CONSTRUÇÃO E DEMOLIÇÃO AVANÇOS RECENTES E DESAFIOS FUTUROS, Anais. São Paulo: Escola Politécnica da Universidade de São Paulo - EPUSP, 2005. p. 1-24.

AMORIM NETO, A. A.; DANTAS, J. O. C. Gipsita. Pernambuco: Balanço Mineral Brasileiro, 2013.

CONSELHO NACIONAL DO MEIO AMBIENTE-CONAMA. Resolução n. 307, de 5 de julho de 2002. Estabelece diretrizes, critérios e procedimentos para a gestão dos resíduos da construção civil. Disponível em: <http://www.mma.gov.br/port/conama/legiabre.cfm?codlegi=307>. Acesso em: 19 mar. 2014.

JOHN, V. M. ; ANGULO, S. C. ; CINCOTTO, M. A. A reciclagem de resíduos de construção e demolição e o gesso. Noticias da Construção, p. 18 - 19, 01 set. 2002.

LYRA SOBRINHO, A. C. P. de et al. Gipsita. Pernambuco: Balanço Mineral Brasileiro, 2011.

PINHEIRO, S. M. de M. Gesso reciclado: avaliação de propriedades para uso em componentes. 2011. 304 f. Tese (Doutorado) - Curso de Arquitetura e Urbanismo, Universidade Estadual de Campinas, Campinas.

QUERINO, B. D.C., et al. Cadeia de suprimentos de mármores e granito na construção civil - um estudo de caso de logística reversa. In: SIMPÓSIO BRASILEIRO DE GESTÃO E ECONOMIA DA CONSTRUÇÃO - INOVAÇÃO E SUSTENTABILIDADE， 8., 2013, Salvador. 